\title{
Assessment of knowledge, attitude, and practice of nursing management of birth asphyxia in federal medical centre Asaba, Delta State-Nigeria
}

\author{
Ezenduka P.O. ${ }^{1}$, Ndie E.C. ${ }^{* 2}$, Oburoh E.T. ${ }^{3}$ \\ ${ }^{1}$ Department of Nursing Science, Nnamdi Azikiwe University, Nnewi Campus, Nigeria \\ ${ }^{2}$ Departement of Nursing Science, Ebonyi State University, Abakaliki, Nigeria \\ ${ }^{3}$ Federal Medical Center Asaba, Delter State, Nigeria
}

Received: September 5, 2015

Accepted: February 17, 2016

Online Published: February 26, 2016

DOI: $10.5430 /$ cns.v4n2p21

URL: http://dx.doi.org/10.5430/cns.v4n2p21

\begin{abstract}
This study aimed at assessing the knowledge, attitude and practice of nursing management of birth asphyxia in Federal Medical Centre Asaba, Delta State, Nigeria. It was a descriptive survey study of 50 nurses selected by purposive sampling technique from the Maternity and Neonatal Units of the centre. Self-structured questionnaire was used to collect data from the nurses on the key aspects of the management of birth asphyxia. The instrument was used in a pilot study in Female medical ward and test retest correlation coefficient was 0.76 . Permission was obtained from the ethical committee of the centre, and unit Heads of Maternity and Neonatal wards. The result revealed that years of experience has no significant effect $(p>.05)$ on the nurses level of knowledge of nursing management of birth asphyxia and that only $10 \%$ of nurses adopted appropriate practice level. The results also show that There is no significant difference $(p>.05)$ in attitude of nurses to the practice of management of birth asphyxia. Refresher courses were recommended for nurses to improve the level of good practice in care of birth asphyxia.
\end{abstract}

Key Words: Assessment, Knowledge, Attitude, Practice, Management, Birth asphyxia

\section{INTRODUCTION}

The birth of a healthy newborn is one of the finest gifts of nature. The birth process takes only few hours but it is the most hazardous period of life since it is associated with the largest number of deaths as compared to any other phase of life. At birth, the baby has to adapt from uterine life to outside uterine life. All the body systems under go some changes. Respiration is stimulated by low carbon dioxide within the blood. ${ }^{[1]}$ The first one minute after birth which is regarded as the "golden minute" the baby should be breathing well. The failure of the new born to establish and sustain respiration at one minute of life results to the condition known as birth asphyxia. It is a condition in the new born where there is reduced oxygen saturation (hypoxemia) and increased acid in the blood (academia) from carbon dioxide retention and lactic acid accumulation. Birth asphyxia is recognized as an important cause of neonatal morbidity and mortality especially in developing countries. ${ }^{[2]}$ Globally, birth asphyxia has continued to pose a major clinical problem with approximately one million babies affected annually. In developing countries, it is a major cause of death and acquired brain damage with rates ranging from 4.6 per 1,000 in Cape Town to 26 per 1,000 in Nigeria with case fatality rates of about $40 \%$ or higher. ${ }^{[3]}$ Nigeria.

*Correspondence: Ndie E.C.; Email: chubike05@yahoo.com; Address: Departement Of Nursing Science, Ebonyi State University, Abakaliki, 
Factors responsible for asphyxia in the new born may be due to maternal risk factors such as pre-eclampsia, eclampsia, premature rupture of membrane, anaemia, and maternal diabetes. During labour, risk factors include prolonged labour, breech or other abnormal presentations, precipitous labour and prolapsed cord. Also asphyxia in the new born may occur from severe cardiopulmonary abnormalities or prematurity. ${ }^{[4]}$

Nursing assessment of the baby at birth, help to identifying the need for resuscitation early and the skillful resuscitation of the asphyxiated new born to restore health and prevent further complications may depend on the three inter related factors of Knowledge, Attitude and Skillful Practice of the nurses. Knowledge is the condition of knowing something with familiarity gained through experience or association. ${ }^{[5]}$ Adequate knowledge and awareness about neonatal resuscitation plays a major role in early diagnosis, appropriate management and reduction of adverse consequences resulting from birth asphyxia. ${ }^{[6]}$ Attitude also influences individual's choice of action and responses to challenges, incentives and rewards. Attitude may be affective relating to emotions or feelings linked to an object, cognitive relating to beliefs, thoughts and attributes that is associate with an object. Positive attitude of nurses help in successful nursing practice. Nursing practice is an act of providing care to patients and in so doing nurses implement nursing care plan which is based on the conditions of the patient, ${ }^{[7]}$ identified inappropriate practices in our health care system as a contributory factor to the occurrence and severity of birth asphyxia. Therefore, nurses' knowledge of birth asphyxia and its associated problems as well as the caring attitude and skills in managing the condition is essential for reducing the mortality and morbidity.

The goals of management include early identification of risk factors of asphyxia so that resuscitative measures can be instituted early at birth. This should be evidence based with goal directed actions that address most of the prevalent health issues affecting women and new born such as socioeconomic, health profile and history physical examination and testing of urine. Emphasis is placed on quality rather than number of visits. ${ }^{[8]}$ Since nurses have the first contact with the babies at birth in our health institutions ignoring them may amount to inadequate or low level of care, poor out comes, increased death rates and persistent high rates of infant mortality as we have it today in Nigeria. This study therefore intends to assess the knowledge, attitude and practices of nurses on the management of birth asphyxia in order to discover gaps that impede successful reduction in the neonatal death in Nigeria. The null hypotheses of no significant differences in the years of practice on the knowledge, attitude and practice of the management of birth asphyxia was tested.

\section{Methodology}

The descriptive survey research design was used to assess the level of knowledge, attitude and practices of nursing management of birth asphyxiated babies.

The population for the study consisted of 50 nurses - comprising 30 nurses from the maternity unit and 20 nurses from the neonatal unit of the hospital that were present and willing to participate in the study. They were all used for the study because of the small size of the population, so convenient sampling technique was used. Self-developed four item structured on the areas of knowledge, attitude and practices of nursing management of birth asphyxia questionnaire was used as instrument for the study. The instrument after review by senior colleagues it was used for a pilot study in Female medical Ward and test and retest was used to verify the reliability of the instrument. The correlation coefficient was 0.76. Section A consists of socio-demographic questions comprising of seven items to obtain information on age, professional qualifications, area of specialization, years of working experience, training on neonatal resuscitation, if any number of training and how long was the last training.

Section B consists of structured questions on knowledge about birth asphyxia. The knowledge part consists of 15 questions which covers general information on birth asphyxia and newborn care. It is measured by multiple choices, true or false and filling the gaps. A score of one (1) was assigned for correct answer and score zero (0) was assigned for improper answer. Maximum possible score in section B is 15 .

Section C consists of 20 structured items on nursing care practices formulated to assess the practices of nurses in the management of birth asphyxia. Areas included in this section were preparation for birth and resuscitation practices. It is measured by multiple choice questions. A score of one (1) was assigned for correct answer and score zero (0) was assigned for improper answer. Maximum possible score in section $\mathrm{C}$ is 20 . Section D consists of rating scale to assess the attitude of nurses on neonatal resuscitation of asphyxiated babies. The attitude questions consist of 10 statements identifying the attitudes of respondents towards neonatal resuscitation and care of asphyxiated babies. This section utilized a four-point Likert scale to assess attitude in term of strongly agree (SA), agree, disagree and strongly disagree (SD). The questions were scored with 4 points for SA, 3 for agree, 2 for disagree and 1 for SD. Therefore, since the questions were 10 and the highest point on the LIkert scale is 4 the highest possible score is 40 that is $10 \times 4=40$. An approval to collect data was sought and obtained from the

ISSN 2324-7940 E-ISSN 2324-7959 
ethical review committee of Federal Medical Centre Asaba before commencement of the study. The participants were assured that all information provided by them will be kept confidential. The researchers ensured that participation in the study was a voluntary and only the participants that gave their informed consent participated in the study. The instrument was administered by researchers themselves when the respondents were on duty. The basic tool used for the analysis of data was SPSS version 20. Descriptive and inferential of means and percentages were used as well as Chi-square for test of hypothesis.

\section{Results}

The data in Table 1 revealed that majority 22 (44\%) of the respondents fall within 31-40 years, others 15 (24\%) and $1(2 \%)$ were within $21-30$ years, $41-50$ years and above
51 years respectively. A large proportion 21 (42\%) of the respondents were registered Nurse/Midwife, 6 (12\%) were registered nurses, 10 (20\%) were registered Midwives, $5(10 \%)$ were Paediatric nurses and $8(16 \%)$ were Bachelor of science (B.Sc) nurses. Years of practice ranged from 1-30 years. Majority 17 (34\%) fall within 6-10 years, 11-15 years, 16-20 years and 21-30 years of practice respectively. Also, 19 $(38 \%)$ of the respondents had neonatal resuscitation training, $21(42 \%)$ had no training while there was no response from $10(20 \%)$ of the respondents. $16(32 \%)$ of the respondents had at least one training in neonatal resuscitation while 3 $(6 \%)$ had two trainings periods. $3(6 \%)$ had their last training less than a year ago, 7 (14\%), $2(4 \%)$ and $5(10 \%)$ had their last training between 1-2 years, 3-4 years and more than 5 years ago.

Table 1. Socio-demographic characteristics $(\mathrm{N}=50)$

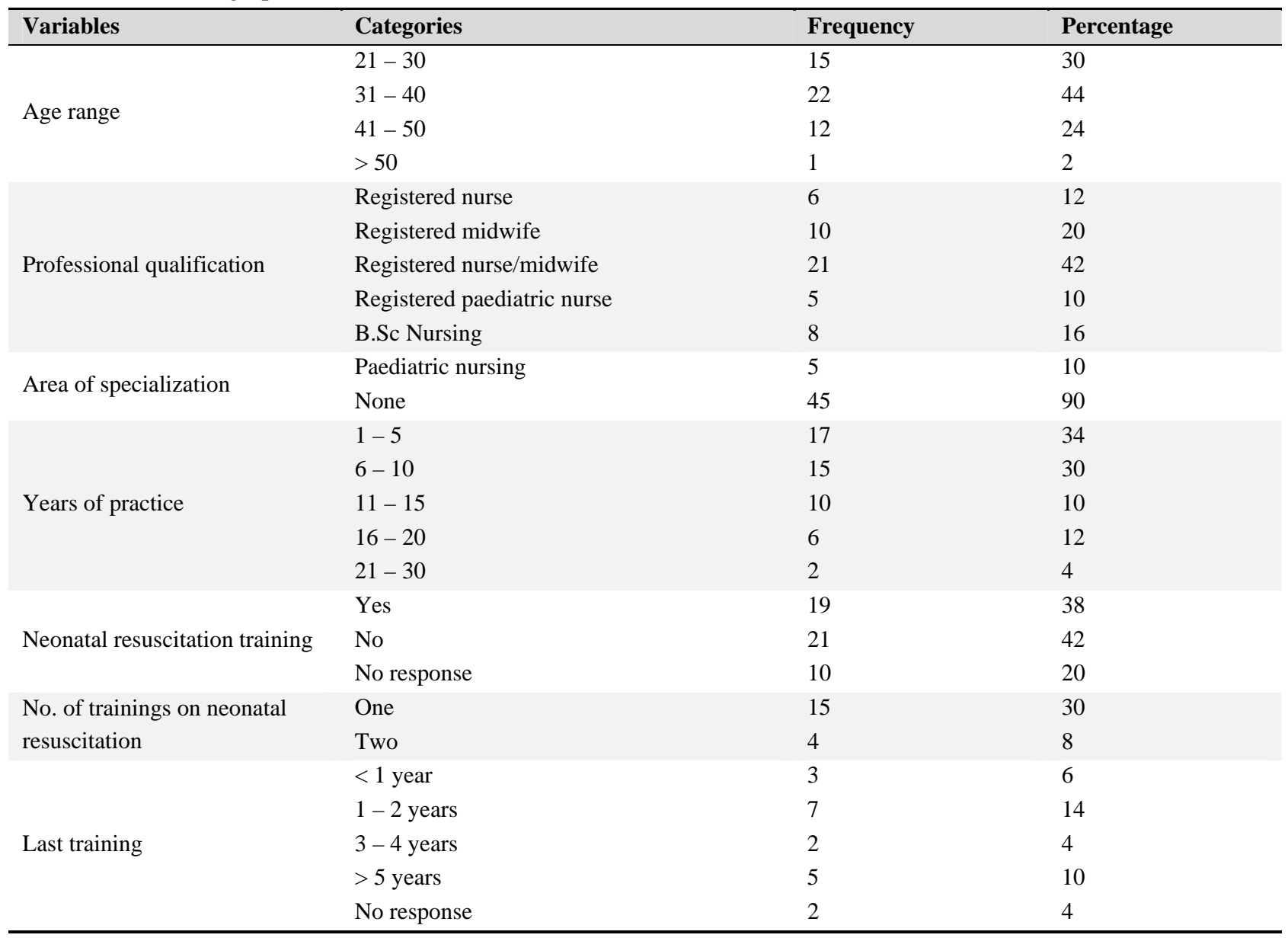

The maximum obtainable score for knowledge was 15 . The mean scores for knowledge of respondents for each demographic variable were obtained. The respondents scored from 2-15 with an overall mean and standard deviation of 10.1
(2.3) respectively. The results also showed that the mean and standard deviation scores of respondents according to their age range were; 10.7 (2.25), 9.2 (2.9) and 10.3 (1.4) for 21-30, 31-40, and 40 years respectively. Mean and deviation 
standard scores regarding the qualification of respondents 10.5 (2.5), $9.4(2.7), 10.4$ (2.0), 8.3 (3.3) and 12 (0) for 1-5, were 9.5 (2.9), 10.1 (2.4), 9.9 (2.3), 11.4 (2.0) and 9.8 (3.3) 6-10, 11-15, 16-20 and 21-30 years of practice accordingly. for registered nurse $(\mathrm{RN})$, registered midwife $(\mathrm{RM})$, reg- With regard to neonatal resuscitation training, respondents istered nurse/midwife (RN/M), registered paediatric nurse scored $9.6(2.9)$ and 10.1 (2.3) for those with and without (RPdN), and B.Sc Nursing respectively. Respondents scored training respectively (see Table 2).

Table 2. Mean and standard deviation of knowledge scores for nurses by age, qualification, years of practice and neonatal resuscitation training $(\mathrm{N}=50)$

\begin{tabular}{llllll}
\hline & Variables & Frequency & Percent & Mean score & STD \\
\hline \multirow{3}{*}{ Age in years } & $21-30$ & 15 & 30 & 10.7 & 2.3 \\
& $31-40$ & 22 & 44 & 9.2 & 2.9 \\
& $41-50$ & 13 & 26 & 10.3 & 1.4 \\
Qualification & RN & 6 & 12 & 9.5 & 2.9 \\
& RM & 10 & 20 & 10.1 & 2.4 \\
& RN/M & 21 & 42 & 9.9 & 2.3 \\
& RPdN & 5 & 10 & 11.4 & 2.0 \\
& B.Sc & 8 & 16 & 9.8 & 3.3 \\
Years of practice & $1-5$ & 17 & 34 & 10.5 & 2.5 \\
& $6-10$ & 15 & 30 & 9.4 & 2.7 \\
& $11-15$ & 10 & 20 & 10.4 & 2.0 \\
NRT & $16-20$ & 6 & 12 & 8.3 & 3.3 \\
& $21-30$ & 2 & 4 & 12 & 0 \\
& Yes & 19 & 38 & 9.6 & 2.9 \\
& No & 21 & 42 & 10.1 & 2.3 \\
\hline
\end{tabular}

Note. RN: Registered nurse; RM: Registered midwife; RN/M: Registered nurse/midwife; RPdN: Registered paediatric nurse; NRT: Neonatal resuscitation training

Table 3. Mean and standard deviation of attitude scores for nurses by age, qualification, years of practice and neonatal resuscitation training $(\mathrm{N}=50)$

\begin{tabular}{llllll}
\hline & Variables & Frequency & Percent & Mean scores & STD \\
\hline \multirow{3}{*}{ Age in years } & $21-30$ & 15 & 30 & 27.3 & 11.6 \\
& $31-40$ & 22 & 44 & 29.0 & 6.4 \\
& $41-50$ & 13 & 26 & 26.0 & 12.9 \\
Qualification & RN & 6 & 12 & 24.8 & 12.9 \\
& RM & 10 & 20 & 26.2 & 5.3 \\
& RN/M & 21 & 42 & 27.5 & 12.4 \\
& RPdN & 5 & 10 & 32.0 & 3.2 \\
& B.Sc & 8 & 16 & 28.0 & 9.3 \\
Years of practice & $1-5$ & 17 & 34 & 27.2 & 10.6 \\
& $6-10$ & 15 & 30 & 31.9 & 5.6 \\
& $11-15$ & 10 & 20 & 29.6 & 6.2 \\
& $16-20$ & 6 & 12 & 16.3 & 15.1 \\
NRT & $21-30$ & 2 & 4 & 23.5 & 2.1 \\
& Yes & 19 & 38 & 24.3 & 12.9 \\
\hline & No & 21 & 42 & 29.7 & - \\
\hline
\end{tabular}

Note. RN: Registered nurse; RM: Registered midwife; RN/M: Registered nurse/midwife; RPdN: Registered paediatric nurse; NRT: Neonatal resuscitation training 
The maximum obtainable score for attitude question was 40 . The four point likert scale was employed. The mean scores and standard deviation for attitude of respondents for each demographic variable was obtained. The respondents scored from 2-40 with an overall mean and standard deviation of 26.8 (9). The results as revealed in Table 3, showed that respondents had mean and standard deviation scores of 27.3 (2.6), 29.0 (6.4) and 26 (12.9) for age groups of 21-30, 31-40, and 41-50 years respectively. Regarding respondents qualifi- cations, mean and standard deviation scores were; 24 (12.9), 26.2 (5.3), 32 (3.2) and 28 (9.3) for RN, RM, RN/M, RPdN, and B.Sc Nursing respectively. Years of practice scores were; 27.2 (10.6), 31.9 (5.6), 29.6 (6.2), 16.3 (15.1) and 23.5 (2.1) for $1-5,6-10,11-15,16-20$ and 21-30 categories respectively. On neonatal resuscitation training, respondents with and without training scores were 24.3 (12.9) and 29.7 (8.2) respectively.

Table 4. Mean and standard deviation of attitude scores for nurses by age, qualification, years of practice and neonatal resuscitation training $(\mathrm{N}=50)$

\begin{tabular}{|c|c|c|c|c|c|}
\hline & Variables & Frequency & Percent & Mean scores & STD \\
\hline \multirow{3}{*}{ Age in years } & $21-30$ & 15 & 30 & 8.1 & 2.5 \\
\hline & $31-40$ & 22 & 44 & 8.1 & 1.4 \\
\hline & $41-50$ & 13 & 26 & 5.5 & 3.3 \\
\hline \multirow{5}{*}{ Qualification } & $\mathrm{RN}$ & 6 & 12 & 6.5 & 2.0 \\
\hline & $\mathrm{RM}$ & 10 & 20 & 8.1 & 1.7 \\
\hline & $\mathrm{RN} / \mathrm{M}$ & 21 & 42 & 7.0 & 2.9 \\
\hline & $\mathrm{RPdN}$ & 5 & 10 & 8.2 & 2.2 \\
\hline & B.Sc & 8 & 16 & 7.4 & 1.8 \\
\hline \multirow{5}{*}{ Years of practice } & $1-5$ & 17 & 34 & 7.6 & 2.6 \\
\hline & $6-10$ & 15 & 30 & 8.1 & 1.0 \\
\hline & $11-15$ & 10 & 20 & 7.4 & 1.3 \\
\hline & $16-20$ & 6 & 12 & 4.8 & 4.2 \\
\hline & $21-30$ & 2 & 4 & 8.0 & 1.4 \\
\hline \multirow{3}{*}{ NRT } & Yes & 19 & 38 & 6.6 & 3.1 \\
\hline & No & 21 & 42 & 7.9 & 1.7 \\
\hline & NR & 10 & 20 & - & - \\
\hline
\end{tabular}

Note. RN: Registered nurse; RM: Registered midwife; RN/M: Registered nurse/midwife; RPdN: Registered paediatric nurse; NRT: Neonatal resuscitation training

Table 5. Contingency Table of the knowledge of nurses in relation to years of practice in the management of birth asphyxia

\begin{tabular}{|c|c|c|c|c|c|c|c|c|}
\hline Category & VG & G & $\mathbf{P}$ & VP & $d f$ & $\chi^{2}$ & $c-r$ & Decision \\
\hline $1-5$ & $9(8.16)$ & $4(5.44)$ & $4(2.72)$ & $0(0.68)$ & & & & \\
\hline $6-10$ & $6(7.2)$ & $6(4.8)$ & $2(2.4)$ & $1(0.6)$ & & & & \\
\hline $11-15$ & $5(4.8)$ & $4(3.2)$ & $1(1.6)$ & $0(0.4)$ & 12 & 9.02 & 18.04 & upheld \\
\hline $16-20$ & $2(2.88)$ & $2(1.92)$ & $1(0.96)$ & $1(0.24)$ & & & & \\
\hline $21-30$ & $2(0.96)$ & $0(0.64)$ & $0(0.32)$ & $0(0.08)$ & & & & \\
\hline Total & 24 & 16 & 8 & 2 & & & & \\
\hline \multicolumn{9}{|l|}{ Category } \\
\hline Knowledge & $36(40)$ & $6(6)$ & $8(4)$ & $0(0)$ & & & & \\
\hline Attitude & $44(40)$ & $6(6)$ & $0(4)$ & $0(0)$ & 3 & 4.8 & 9.6 & upheld \\
\hline Total & 80 & 12 & 8 & 0 & & & & \\
\hline
\end{tabular}

Note. $\mathrm{VG}=$ very good; $\mathrm{G}=$ good; $\mathrm{P}=$ poor; $\mathrm{VP}=$ very poor

The respondents' scores on level of practice in the manage- lation to their age were 8.1 (2.5), 8.1 (1.4) and 5.5 (3.3) for ment of birth asphyxia were from 2-11. The overall mean 21-30, 31-40, and 41-50 years respectively. Though none score was 7.3 and the maximum obtainable score was 20. of the age groups had above average score, the age group The respondents mean and standard deviation scores in re- 41-50 had the lowest mean score of 5.5 (3.3) in this cate- 
gory. With respect to qualification, respondents' scores were: 6.5 (2.0), 8.1 (1.7), 7.0 (2.9), 8.2 (2.2), and 7.4 (1.8) for RN, RM, RN/M, RPdN, and B.Sc Nursing respectively. The $\mathrm{RPdN}$ had the best mean of 8.2 (2.2) which was still below average. Regarding years of practice, respondents scored 7.8 (2.6), 8.1 (1.0), 7.4 (1.3), 4.4 (4.2) and 8 (1.4) for 1- 5, 6-10, $11-15,16-20$ and $21-30$ years of practice respectively. The category of 6-10 years of practice had the highest mean of 8.1 (1.0). In the area of training on neonatal resuscitation, mean scores of respondents were 6.6 (3.1) and 7.9 (1.9) for those with and without neonatal resuscitation training respectively (see Table 4).

Data in Table 5 revealed a $d f$ of 12 and a calculated or observed value of 9.02. It also showed an index value of 18.04 as the critical value $(c-r)$. The figures showed that the critical value was significantly greater than the calculated value. It was therefore an indication that year of service has no significant relationship with nurses' level of knowledge in the management of birth asphyxia. Since the critical value was significantly greater than the calculated value, hypothesis one was upheld and the alternative rejected.

The above table also indicated the index value of 3 as the $d f, 4.8$ as the calculated value and 9.6 as the critical value. The figures revealed that the critical value was significantly greater than the calculated value. These figures also was an indication that those who have VG grade of level of knowledge on the management of birth asphyxia have no different attitude than those with relatively lower grade of level of knowledge. In other words, virtually all nurses have the same attitude to the practice.

\section{Discussion}

Nursing is a profession that deals with human health and thus life. It therefore demands high professional knowledge for effective and efficient management of human health. On research question one, in the course of the study it was revealed that nurses generally irrespective of their age, qualifications, years of experience and neonatal resuscitation training had above averages scores with an overall mean and standard deviation of 10.1 (2.3) indicating good knowledge. Specifically $83 \%$ of nurses involved in the management of birth asphyxia in FMC Asaba have good level of knowledge required for successful management of birth asphyxia. These findings are in contrast with the findings of Tinaude et al. ${ }^{[6]}$ and Murila $e t$ $a l .{ }^{[9]}$ that reported low and substandard level of knowledge. The high level of knowledge observed may be attributed to their training.

Furthermore, though results revealed that nurses involved in the management of birth asphyxia have the required knowl- edge and qualification, it was also observed that registered pediatric nurses recorded the highest mean of knowledge scores 11.4 ( $\mathrm{SD}=1.95)$. The result is not surprising as they had specialized training in pediatric training which others do not have. Although, studies on the relationship between specialization in pediatric nursing and knowledge in management of birth asphyxia is not yet visible, the result of this study is an indication that specialization in pediatrics can positively improve knowledge and improve management of birth asphyxia.

Only about $10 \%$ of the nurses involved in the management of birth asphyxia adopted appropriate high level of practices. This result aligned with those of Suad ${ }^{[10,11]}$ who reported that the practice of nurses on neonatal resuscitation in the delivery room was poor and went further to establish that there was no significant association between nurses' practices and their age, level of education, marital status, years of experience and training in neonatal resuscitation. Inappropriate practices are disastrous and endanger life. This assertion was supported by Lawn et al. ${ }^{[7]}$ who identified inappropriate practices in our health system s as a contributing factor to the occurrence and severity of birth asphyxia.

It further revealed that though attitude and knowledge may be the coordinating forces yet excellence in nursing practices may not be obtainable. ${ }^{[12]}$ Positive attitude and knowledge with poor practice is dangerous as this will continue to support the occurrence of birth asphyxia and its related problems. ${ }^{[13]}$ These findings are in line with the findings of Chikuse et al. ${ }^{[14,15]}$ who concluded that nurses/midwives' non-adherence to guidelines for neonatal resuscitation even when well-informed, account for birth asphyxia.

\section{Conclusions}

The rising incidence in birth asphyxia is an indication of missing links among the indicators of professional nursing practices. These indicators were identified to be years of experience, professional qualifications, attitude of nurses and professional practices. These factors inter-play to bring about quality service in health management. Majority of nurses have very good knowledge of the basic skills needed for the management of birth asphyxia. They also have positive attitudes in managing such cases but lack appropriate ability to put the skills into practices for professional care.

\section{Recommendation}

Based on the findings of the study, the following recommendations were made:

(1) Government should promote professional audits for professional conduct and practices. If this is done,

ISSN 2324-7940 E-ISSN 2324-7959 
nurses and other medical practitioners would be committed to their job.

(2) Refresher courses on professional skills and practices involving lives should be regularly given to nurses, doctors and significant others especially on management of birth asphyxia. This could help reduce complications in birth asphyxia as they could respond more appropriately to such cases timely and aptly.

(3) Mothers delivered of their babies should be as a policy, interviewed by quality assurance committee members (where such exists) on the quality of nursing care offered by the attendant nurses towards her and the neonate during and after delivery. Such steps would make nurses, doctors and significant others wake up to their responsibilities and if possible reduce birth asphyxia.

(4) There should be regular training and retraining for nurses and other birth attendants on neonatal resuscitation.

(5) More nurses should be sponsored to specialize in paediatric nursing.

\section{CONFLICTS OF INTEREST Disclosure}

The authors declare that they have no conflict of interest.

\section{REFERENCES}

[1] Undeshi VA, Ndie EC. Clinical Procedure Guide For Midwife. OJC Academic publishers, Enugu. 2012.

[2] FMOH. Intergrated maternal, new born and child health strategies. Abuja, Nigeria. 2007.

[3] WHO. 2000. The World Health Report 2000 Health Systems: Improving performance. Geneva: World Health Organization.

[4] American Heart Association. BLS for Healthcare Providers. Student manual. 2011.

[5] The New International Webster's comprehensive Dictionary of the English Language. Delux Encyclopedia Edition.

[6] Murila F, Obimbo MM, Musoke R. Assessment of knowledge on neonatal resuscitation amongst health care providers in Kenya. Pan African Medical Journal. 2012; 11(11): 78. PMid: 22655112. Available from: http://www.ncbi.nlm.nih.gov/pmc/article s/PMC3361216/

[7] Lawn JN, Manandhar A, Haws RA, et al. Reducing one million deaths from birth asphyxia: a survey of health systems gaps and priorities. 2007 [Retrieved March 3, 2013]. Available from: http: //www.health-policy-systems. com/content/5/1/4

[8] Ihudiebube-Splendor CN, Ezenduka PO. Focused antenatal care package: an approach to improved quality maternal and newborn care. West African Journal of Nursing. 2010; 21(2): 72.

[9] Tinuade O, Olabisi D, Folasade A, et al. Neonatal Resuscitation : Knowledge and practices of Nurses in western Nigeria. 2008 [Re- trieved 22nd November, 2014]. Available from: http://www . ajol .info/index.php/sajchh/article/view/41845/64291

[10] Suad HK. Evaluation of Nurses' practices Towards Neonatal resuscitation in the Delivery room. 2012 [Retrieved 22nd November, 2014]. Available from: http://www .iasj . net/iasj?func=ful ltext\&ald $=65411$

[11] Ugwu GI, Abedi HO, Ugwu EN. Incidence of birth asphyxia as seen in central hospital and GN children's clinic both in Warri Niger Delta of Nigeria: an eight year retrospective review. Glob J Health Sci. 2012; 4(5): 140-6. http://dx.doi.org/10.5539/gjhs.v4n5p1 40

[12] Ehiemere IO, Ezenduka PO. Attitude of senior hospital management staff to higher education in Enugu, South East Nigeria. West African Journal of Nursing. 2001; 12(1).

[13] Merill JD, Ballard RA. Resuscitation in the delivery room. In: Avery's diseases of the new born 8th Ed. Philadelphia: Lippincott Williams \& Wilkins press; 2011.

[14] Chikuse B, Chiwa E, Maluwa A, et al. Midwives Adherence to guidelines. Malawi Open Journal of Nursing. 2012; 2: 351-357. http://dx.doi.org/10.4236/ojn.2012.24052

[15] Kelley JR. A framework for developing continuing professional education and its application to neonatal resuscitation in the Sultanate of Oman. Journal of Neonatal Nursing. 2005; 11; 18-2 http://dx.doi.org/10.1016/j.jnn.2005.04.005 